\title{
TOWARDS NEXT GENERATION CYBER-PHYSICAL SYSTEMS AND DIGITAL TWINS FOR CONSTRUCTION
}

SUBMITTED: June 2021

REVISED: July 2021

PUBLISHED: July 2021

GUEST EDITORS: Kirti Ruikar, Ketan Kotecha, Sayali Sandbhor, Albert Thomas

DOI: $10.36680 /$ j.itcon.2021.027

\author{
Abiola A. Akanmu, Ph.D \\ Virginia Polytechnic Institute and State University, Virginia, United States \\ abiola@vt.edu
}

Chimay J. Anumba, Ph.D., D.Sc.

University of Florida, Florida, United States

anumba@ufl.edu

Omobolanle O. Ogunseiju, Ph.D. student

Virginia Polytechnic Institute and State University, Virginia, United States

omobolanle@vt.edu

\begin{abstract}
SUMMARY: The construction industry continues to seek innovative ways to safely, timely and cost-effectively deliver construction projects. Several efforts have been made to automate construction processes but marginial success has been achieved in effectively reducing the long standing risks suffered by the industry. While industry 4.0 promises to improve project efficiency, reduce waste and improve productivity, the transition to this will depend on the successful adoption of many emerging technologies such as virtual design modeling technologies, sensing technologies, data analysis, storage and communication technologies, human-computer interaction technologies, and robotics. To accelerate innovation, digital twins and cyber-physical systems will be a necessity to advance automation and real-time control with these technologies. While digital twin represents a digital replica of the asplanned and as-built facility, cyber physical systems involve integration of physical systems with their digital replica through sensors and actuators. Despite evidence of the efficacy of cyber-physical systems and digital twins for reducing non-fatal injuries, enhancing safety management, improving progress monitoring and enhancing performance monitoring and control of facilities, their adoption in the construction industry is still in its infancy. This paper sheds light on the opportunities offered by cyber-physical systems and digital twins in other industry sectors and advocates for their increased deployment in the construction industry. This paper describes cyber-physical integration of emerging technologies with the physical construction or constructed facility as the next generation digital twin and cyber-physical systems. Potential scenarios of next generation cyber physical system and digital twin for improving workforce productivity, health, and safety, lifecycle management of building systems, and workforce competency are presented.
\end{abstract}

KEYWORDS: Cyber-physical systems, digital twins, next generation, virtual models, physical construction

REFERENCE: Abiola A. Akanmu, Chimay J. Anumba, Omobolanle O. Ogunseiju (2021). Towards next generation cyber-physical systems and digital twins for construction. Journal of Information Technology in Construction (ITcon), Special issue: 'Next Generation ICT - How distant is ubiquitous computing?', Vol. 26, pg. 505-525, DOI: 10.36680/j.itcon.2021.027

COPYRIGHT: () 2021 The author(s). This is an open access article distributed under the terms of the Creative Commons Attribution 4.0 International (https://creativecommons.org/licenses/by/4.0/), which permits unrestricted use, distribution, and reproduction in any medium, provided the original work is properly cited. 


\section{INTRODUCTION}

The long-standing issue of poor performance (e.g., low productivity, waste, health, and safety risks) experienced by the construction industry and evidence of the benefits of technological advancement of other industry sectors (e.g., manufacturing and healthcare industries), have triggered an increased awareness and adoption of technology in construction. As a result, there have been documented improvements in the delivery of construction projects and maintenance of constructed facilities (Pradhananga and Teizer, 2013, Zhu et al., 2016). Data-acquisition systems, information technology, and networking technologies have been instrumental to this progressive move in the construction industry. Advances in these technologies have presented opportunities for more synergistic integration of technology with the lifecycle of facilities, providing many benefits including real-time monitoring and improving predictability and control of project outcomes (Akanmu and Anumba, 2015, Ogunseiju et al., 2020, Akanmu et al., 2013) - these are achieved via cyber-physical systems (CPS) and digital twins (DTs). CPS and DTs are increasingly gaining attention from academia and industry. As industries continue to embrace the vision of Industry 4.0, CPS and DTs will be the key drivers for automating processes.

CPS are complex systems that integrate dynamic physical systems/environments with cyber systems. This cyberphysical integration is achieved by combining communication, computing and control to provide real-time monitoring, information feedback, and active control (Liu et al., 2017, Hu et al., 2012). DTs also seek to achieve cyber-physical integration by enabling two-way dynamic mapping between virtual models and physical components, systems, and processes (Tao et al., 2018). DTs enable creation of high-fidelity virtual models of physical components, systems or processes in order to simulate their behaviors and provide feedback (Grieves, 2014). The virtual models can be a supplementary boost to the capability and composition of CPS, making DTs a necessary ingredient for developing CPS, thus creating avenues for realizing the full potential of CPS. Integrating concepts or aspects of DT and CPS would be important in the next generation of CPS. Next generation of CPS will integrate current features of DT with new enabling technologies such as robotics and artificial intelligence to reduce the long standing risks to the delivery and management of buildings and civil infrastructure systems.

This paper describes how the next generation of CPS and DTs can improve construction project delivery process through a cyber-physical integration of emerging technologies with the physical construction/constructed facility. This paper focuses on illuminating the capabilities of both concepts with a view to defining the next generation CPS and DTs and identifying their key features, enabling technologies and application scenarios. This paper is organized as follows: Section 2 reviews the evolution of CPS and DTs, key features, comparisons and applications of both concepts in other industry sectors. Section 3 reviews the applications and limitations of CPS and DTs in the construction industry. Next generation CPS and DTs is presented in Section 4. This includes the enabling technologies and application scenarios. This is followed by discussions and conclusions in Section 5.

\section{CYBER-PHYSICAL SYSTEMS AND DIGITAL TWINS}

The growth of ubiquitous computing and sensing technologies have contributed immensely to the emergence and advancement of CPS and DTs. The evolution of both concepts are provided as follows:

\subsection{Evolution of CPS}

The term Cyber-Physical Systems (CPS) originated from the National Science Foundation (NSF) and was used to describe complex systems whose functionality, performance and effectiveness exceed those of traditional IT systems (Tao et al, 2019). Since then, there have been several attempts to define and set a direction for CPS. For example, Rajkumar et al. (2010) defined CPS as 'physical and engineered systems whose operations are monitored, coordinated, controlled and integrated by a computing and communication core'. Shankar Sastry from University of California, Berkeley defined CPS as 'integration of computing, communication and storage capabilities with monitoring and/or control of entities in the physical world, and must do so dependably, safety, securely, efficiently and in real-time' (Sanislav and Miclea, 2012). Providing a less complex definition, Lee and Seshia (2011) described CPS as a tight integration of computational resources with physical processes. Other authors (Lu et al., 2015, Wan et al., 2011) have viewed CPS as networking of technological systems, characterized as embedded, distributed and real-time systems, with advances in sensors and actuators. To meet the overarching goal of maintaining consistency between as-planned models and as-builts in the construction domain, Anumba et al. (2010) built on Shankar and Rajkumar's definitions to describe CPS as the tight integration and bi-directional 
coordination between virtual design models and the physical construction/constructed facility. This definition has since been employed by existing CPS studies in construction (Jiang et al., 2020b, Eskandar et al., 2020).

\subsection{Evolution of DT}

Michael Grieves is considered the first person to use the term DT, during a lecture on product lifecycle management at the University of Michigan in 2003 (Grieves, 2014). Since then, a variety of definitions have evolved. The definitions have been based on the specific contexts to which the concept of DTs have been applied (Wagner et al., 2019). The earliest definition of DTs was provided by Grieves as physical components, products, or systems in physical space, their corresponding virtual representations in virtual space, and the information flowing between both spaces (Tao et al., 2019). The information has been referred to as comprehensive physical and functional description of the physical component, product or system, required throughout the lifecycle phases (Grieves and Vickers, 2017, Boschert and Rosen, 2016). DTs have also been referred to as mirrors (reflections or virtual replica) of physical systems that characterize their real time behavior (Rosen et al., 2015, Tharma et al., 2018, Jiang et al., 2020a). Glaessgen and Stargel (2012) extended Rosen and Grieve's definitions to include a detailed process of achieving DTs for space vehicles by describing DT as 'an integrated multi-physics, multiscale, probabilistic simulation of an as-built vehicle or system that uses the best available physical models, sensor updates and fleet history'. In an attempt to meet the real-time control requirements of industry 4.0, Vatn (2018) suggested that DT should be able to predict the response of physical systems to uncertainties. As such, Vatn (2018) defined DT as 'a digital replica of physical assets, processes and systems that can be used in real-time for control and decision purposes'. To improve the predicting capabilities, DT will need to be updated over time with data provided by sensors installed on the physical system. DT has also been defined in terms of the key enabling technologies that facilitate interaction between physical systems and virtual spaces i.e., data acquisition, data mapping and data-based prediction technologies (Lu et al., 2020).

\subsection{Comparison of CPS and DT}

The definitions show that CPS and DTs are similar as they both advocate an integration of cyber and physical systems. However, there are differences between both concepts. Table 1 presents the similarity and differences between CPS and DT.

Table 1: Comparison of CPS and DT (Tao et al., 2019).

\begin{tabular}{|l|l|l|}
\hline Criteria & CPS & DT \\
\hline Origin & Proposed by Helen Gill at NSF in 2006 & Presented by Michael Grieves in 2003 \\
\hline Interaction type & Cyber and physical interaction & Cyber and physical interaction \\
\hline Interaction level & One-to-many components interaction & One-to-one component interaction \\
\hline Core elements & $\begin{array}{l}\text { Computation, communication, and } \\
\text { control }\end{array}$ & Computation and communication \\
\hline Control means & Models and actuators & Models \\
\hline
\end{tabular}

Although CPS and DT were proposed between 2002 and 2007, DT did not receive enough attention until 2012, whereas, since CPS was proposed, it has been significantly investigated by academia and governments. Both CPS and DTs involve an interaction between cyber and physical systems. Through the cyber and physical interaction, both concepts aim to achieve consistency. However, DT focuses on one-to-one interaction between a physical entity/system/operation and the corresponding virtual entity/system/operation, while CPS emphasizes interaction at multiple scales which can result in one-to-many interactions. The core elements of CPS are communication, computing, and control enabled by sensors and actuators. These facilitate interaction between cyber and physical systems through the exchange of data. The control can be achieved through active control and passive control (i.e., by humans making decisions to alter the state of the physical system) (Akanmu et al., 2014, Broy, 2013). DT is heavily reliant on the development of models from data and the use of the models to predict and control the behavior of physical systems. Finally, given that DT would typically represent the complete as-built system/facility (i.e., a combination of virtual design model and data), the next generation CPS in construction would be driven by the use of such DTs and emerging technologies to control physical construction systems/facilities. 


\subsection{Key features of CPS and DT}

Conceptually, DT can be regarded as a specific type of CPS as it also involves fusing physical components or systems with their corresponding virtual representation using computational resources. For CPS and DTs to exist, there needs to be a 'cyber-to-physical' bridge and 'physical-to-cyber' bridge as shown in Fig. 1. In the 'physicalto-cyber' bridge, data describing the status and condition of the physical system are captured using sensing technologies and data acquisition technologies. In the 'cyber-to-physical' bridge, computational resources use the data to estimate and communicate the control to the physical system (Fawzi et al., 2014, Liu et al., 2020a). However, the nature of the 'cyber-to-physical' bridge slightly differs in each concept. Controls in DTs are achieved using models to predict future states and risks, so that decisions can be made in a timely manner (also referred to as passive control). In CPS, the control can be active or passive. In active control, physical devices in the form of actuators are initiated to control the state of the physical system.

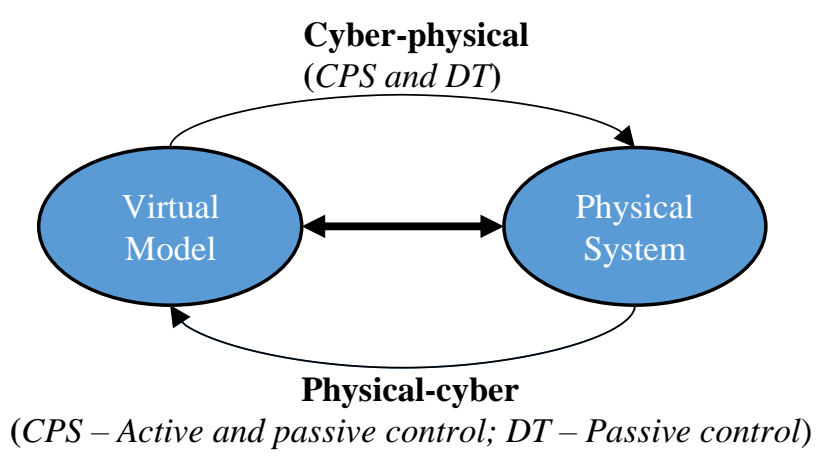

FIG. 1: Interaction between virtual model and the physical entity.

\subsection{CPS and DT applications in other industry sectors}

Table 2 presents a summary of some CPS and DT applications in other industry sectors. These are discussed below.

\subsubsection{CPS in other industry sectors}

Though still at its early stages, CPS is revolutionizing different industries such as manufacturing, healthcare, and transportation through an integrated control, communication, and computational system. For example, in order to achieve mass production, and improve global marketing in the manufacturing industry, CPS has been explored as an approach to providing smart manufacturing for productivity optimization (Gunes et al., 2014). Lee et al. (2015) described a 5-level system architecture for implementing CPS in the manufacturing industry. They explained the integration of configuration, cognition, cyber (twin model), data-to-information conversion, and smart connection levels for successful implementation of CPS.

Similarly, Möller and Vakilzadian (2016) described the use of CPS for achieving smart transportation, improving traffic control systems, control command, and information flow. They explored the characteristics of CPS for achieving smart traffic light and traffic flow systems and transportation such as sensors, actuators, and appropriate communication network. Yongfu et al. (2012) presented a detailed architecture in relation to computation, communication, and control for transportation CPS with the aim of improving and providing safe and quality service to humans. However, Hou et al. (2015) identified privacy concerns, security, cost of testing systems, inoperability, access to software and hardware as challenges to the advancement of CPS. With this context, they described the design and implementation of an integrated traffic-driving-network simulator for evaluating the efficacy of a transportation CPS. While these studies are peculiar to road transportation, some efforts have been made in aviation. For example, Sampigethaya and Poovendran (2013) explored the required functionalities for establishing cyber and physical interactions in aviation to improve flight safety and airworthiness of airplanes.

Likewise, CPS has been explored for medical science and healthcare. For example, Rao et al. (2017) described a case study of medical devices as cyber-physical systems with embedded threat detector for real-time risk mitigation. Fu et al. (2017) explored the enhancement of information for medical CPS by developing a mathematical model that allows more precise prediction of human interactions to improve the potential of medical CPS. 


\subsubsection{DT in other industry sectors}

While CPS is more concerned with the use of sensors and actuators to enable the integration of the physical and cyber worlds, DT focuses on models and data transmission between the physical artifact and the digital model (Kritzinger et al., 2018, Tao et al., 2019). Compared to CPS, limited work has been done in DT across different industries (Table 1). In the manufacturing industry, Bottani et al. (2017) presented a prototype DT of automated guided vehicles for optimizing adaptive behavior of production systems. Brenner and Hummel (2017) explored how DT can be harnessed for shop floor management system for a logistic learning factory. Schleich et al. (2017) presented a conceptual framework of a DT model that integrates design and manufacturing of products in production engineering. In medical sciences, DT has been explored for achieving personalized health care. Liu et al. (2019) proposed a digital twin healthcare system that supervises, diagnoses, and predicts the well-being of elderly people. Similarly, Karakra et al. (2019) presented a DT framework of a hospital where healthcare providers can administer virtual health supervision, diagnostics, and future predictions based on patients' data.

\subsubsection{CPS and DT in other industry sectors}

Some authors such as Wang et al. (2011) have stated that specification of inaccurate data and implementation errors can hinder the rapid adoption of CPS. This informs the need to further enhance seamless, integrated, and accurate information flow between the cyber object and its physical representation. Researchers have started exploring means of harnessing the features of CPS and DT in different disciplines. Some of these studies include the works of Lee et al. (2020), who proposed a deep learning DT and CPS framework for advancing smart manufacturing. Similarly, Park et al. (2020) proposed a DT and CPS-based architecture developed from a productdata-rich model for achieving personalized production. The authors identified the potential of the presented framework as mitigating performance costs of personalized production in the manufacturing industry. These studies commonly reveal the importance of combined CPS and DT for attaining smart and revolutionized Industry 4.0. However, a paucity of studies have assessed the potential of integrating CPS and DT in the construction industry.

Table 2. Review of cyber physical systems and digital twin in other industry sectors.

\begin{tabular}{|c|c|c|c|}
\hline Disciplines & References & $\begin{array}{l}\text { Level of } \\
\text { integration }\end{array}$ & Area of focus \\
\hline \multirow[t]{3}{*}{ Transportation } & $\begin{array}{l}\text { (Möller and Vakilzadian, } \\
\text { 2016) }\end{array}$ & \multirow{3}{*}{ CPS } & Smart traffic light and traffic flow systems \\
\hline & \begin{tabular}{|l}
$\begin{array}{l}\text { Weining, and Xuebo } \\
(2012)\end{array}$ \\
\end{tabular} & & $\begin{array}{l}\text { System architecture of service-oriented } \\
\text { cyber physical system. }\end{array}$ \\
\hline & Hou et al. (2015) & & $\begin{array}{l}\text { Framework for evaluating transportation } \\
\text { cyber physical system }\end{array}$ \\
\hline Aviation & $\begin{array}{|ll|}\text { Sampigethaya } & \text { and } \\
\text { Poovendran (2013) } & \\
\end{array}$ & CPS & Aircraft safety. \\
\hline Manufacturing & (Gunes et al., 2014) & CPS & Smart manufacturing \\
\hline \multirow[t]{2}{*}{ Medical sciences } & Rao et al. (2017) & \multirow[t]{2}{*}{ CPS } & Risk management \\
\hline & Fu et al. (2017) & & $\begin{array}{l}\text { Human interaction assumptions in } \\
\text { medicine }\end{array}$ \\
\hline \multirow[t]{2}{*}{ Manufacturing } & Bottani et al. (2017) & \multirow[t]{2}{*}{ DT } & $\begin{array}{l}\text { Optimizing behaviors of automated } \\
\text { vehicles }\end{array}$ \\
\hline & \begin{tabular}{|l}
$\begin{array}{l}\text { Brenner and Hummel } \\
(2017)\end{array}$ \\
\end{tabular} & & Shop floor management system \\
\hline \multirow[t]{2}{*}{ Healthcare } & Liu et al. (2019) & \multirow[t]{2}{*}{ DT } & Personalized elderly healthcare \\
\hline & Karakra et al. (2019) & & Hospitals \\
\hline
\end{tabular}

\section{CPS AND DT APPLICATIONS IN CONSTRUCTION}

\subsection{Context for CPS and DTs in construction}

With the increasing demand for rapid project turnaround and improved quality, construction has shifted from the traditional project delivery processes to smarter processes that employ diverse automated technologies (Asadi et al., 2020, Melenbrink et al., 2020). Modern construction strives to maintain consistency between as-planned design 
models and the as-built construction. This can be effectively achieved via CPS and DTs, which seek to facilitate a tight integration and coordination between virtual models and physical construction/constructed facility to maintain consistency. The following sections describe existing applications of CPS and DTs in construction.

\subsection{CPS applications in construction}

There have been several efforts on the deployment of CPS to improve various aspects of construction such as project status tracking, safety, as-built documentation, and facility control. These are shown in Fig. 2 and described below.

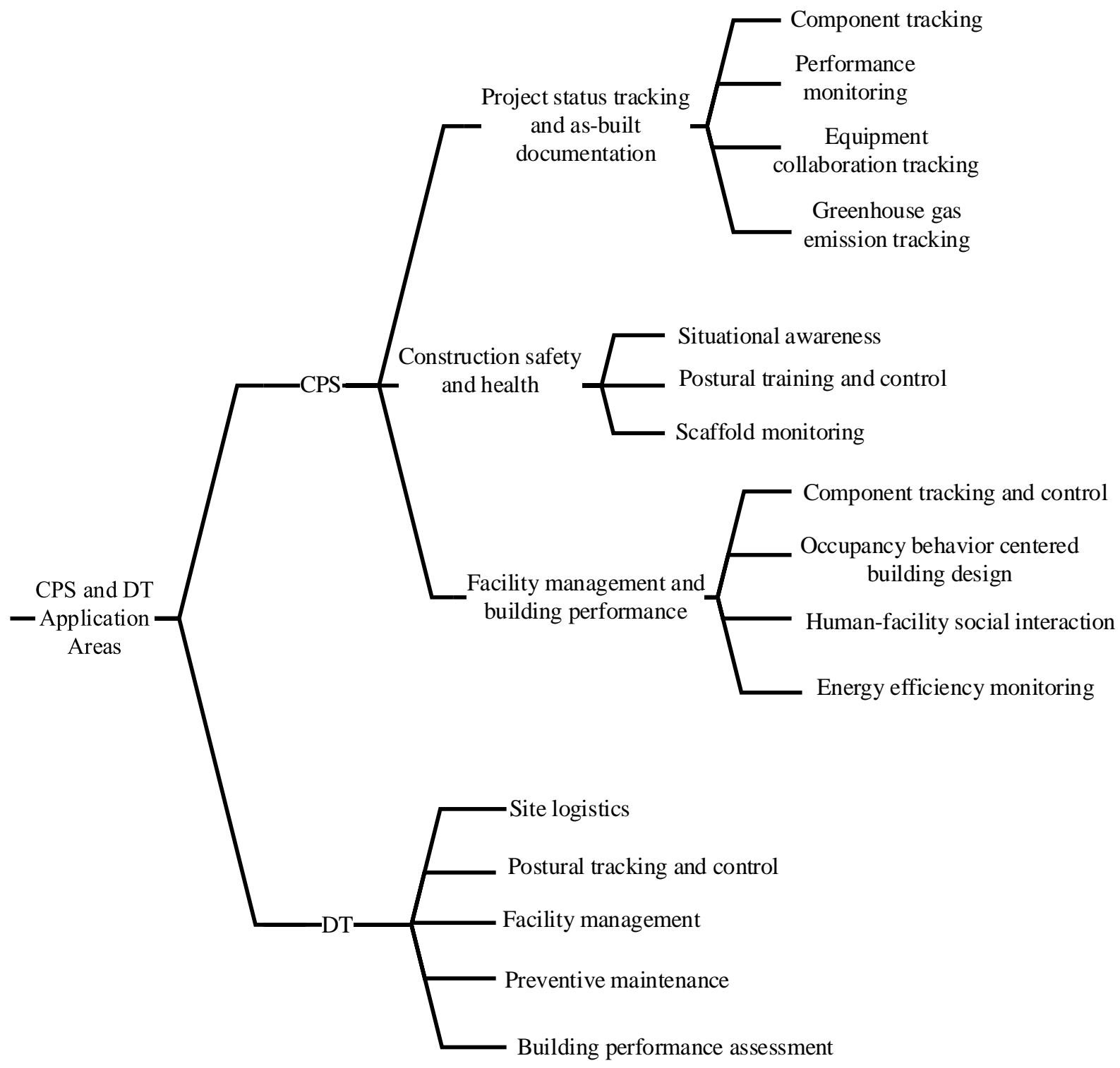

FIG. 2: Application areas of CPS and DT.

\subsubsection{Project status tracking and as-built documentation}

One of the earliest applications of CPS in the construction domain was introduced by Anumba et al. (2010). The authors tracked the status of construction components (such as structural steel members, pumps and doors) by integrating virtual design models and the physical construction using active radio-frequency identification (RFID) 
tags (Akanmu et al., 2013, Akanmu and Anumba, 2015). Olatunji and Akanmu (2015) proposed a CPS platform that uses real-time location sensing RFID system to track construction processes and resources within spatially mapped activity areas. The coordinates of the resources are used to update the cost and schedule status of the project within the BIM model. Lin and Golparvar-Fard (2020) illustrated how image-based sensors (such as laser scanners and cameras) can be leveraged for capturing project progress and enhancing activity reporting. You and Feng (2020) proposed a CPS framework that uses heterogenous data from different sensing systems to create a DT of the construction site which when tightly integrated with the physical construction site, provides project stakeholders with information for controlling construction work. To control the quality of compaction of rollers working in the same area on megaprojects, Liu et al. (2020b) developed a CPS system for tracking and facilitating collaborative compaction. The developed system tracks the status and compaction parameters of each roller and communicates warning messages that would help coordinate the operations of multiple rollers to the operators. To understand the environmental impacts of construction projects, Liu et al. (2020c) developed a CPS system for realtime monitoring and visualization of the greenhouse gas emissions of prefabricated construction.

\subsubsection{Construction safety and health}

Construction projects have long been known to be prone to accidents significantly affecting workers' safety and wellbeing. To address risks that may impact the safety of construction projects, Jiang et al. (2020b) developed a framework for tracking triggers of inconsistencies between physical construction activities and their virtual representations in a simulation model. Genders et al. (2016) proposed improving situational awareness of workers by tracking their location and alerting them of possible collisions via their phones. Anumba et al. (2021) also hypothesized that improving the situational awareness of workers can provide crane operators with real-time feedback. The failure of temporary structures can also pose significant risks to the safety of workers. Using scaffolding as an example, Yuan et al. (2014) showed that potential failure or performance issues can be predicted by tracking and assessing the condition of scaffold members using CPS.

The transfer of training is more effective when training is conducted in similar ways and environments as the real world. However, construction workers have limited opportunities to try out existing training (Moore et al., 2011, Albers, 2007) and receive feedback based on their performance. Akanmu et al. (2020) addressed this by designing a virtual reality (VR)-based training environment where workers can learn to perform work using safe postures. The postural training environment tracks workers' engagement with physical construction resources and provides feedback via a user interface within VR. Sivanathan et al. (2014) demonstrated that workers' postures can be improved if equipped with feedback in the form of warnings and corrections. The nature of the feedback and how they are delivered to workers, could influence the response of the workers.

\subsubsection{Facility management and building performance}

Facility management is aimed at maintaining and adapting buildings to the needs of the users (Barrett and Baldry, 2009). One way to effectively achieve this is by enhancing the monitoring and control of building components. Akanmu et al. (2014) achieved this by binding digitally addressable light fixtures with their virtual representations. In this way, the status of tagged fixtures can be tracked during the construction phase for monitoring and controlling the fixtures during the operations and maintenance phase. Kavulya et al. (2011) presented a framework to bridge the cyber-physical gap during decision making at the conceptual phases of a project lifecycle, by incorporating feedback on occupancy behavior for optimized building designs. Terreno et al. (2020) proposed a framework that advocates including social systems into cyber-physical facility management processes by considering feedback from building occupants and facility managers. Bonci et al. (2019) developed a BIM based CPS system that exploits the self-configuration and self-organization features of holons to determine the most suitable corrective actions for improving facilities. Lessons learnt and suggestions obtained from the evaluation of building efficiency are stored in BIM model. The historical diagnoses stored in the model supports decision making during facility management and renovation. By surveying recent studies in building automation, data analytics and distributed control, Schmidt and Åhlund (2018) developed research questions aimed at evolving buildings into energy efficient predictive CPS.

\subsection{DT applications in construction}

The concept of DT is yet to be fully explored in construction. Some of the few studies include the following: Kan and Anumba (2019) reviewed applications and research opportunities of DT in the construction domain. They 
identified DT as being critical for improving processes involved in the project lifecycle, specifically during design, construction, and operations and maintenance phases. Since the conception of buildings and infrastructure systems commence from the design phase, Boje et al. (2020) developed a framework for extending BIM to DTs in construction. Several technologies and techniques such as sensors, simulation models, and artificial intelligence, were proposed as instrumental for enhancing the capabilities of BIM as a DT of facilities. Greif et al. (2020) presented the concept of a digital silo twin framework to aid construction site logistics and further explored the potentials of the concept with building materials suppliers.

Behavior-based safety theory suggests that workers' ability to perform work safely can be improved through personalized feedback. Akanmu et al. (2020) proposed a DT framework for reducing musculoskeletal injuries amongst the construction workforce through two-way mapping between workers' postures and their corresponding digital representation. The framework tracks kinematics of workers' body segments, assesses the ergonomic exposures of the body-segments, and communicates the ergonomic risks in an actionable format via an augmented virtual replica within the field of view of the worker. In the operations and maintenance phase, DT has been applied to facility management (Xie et al., 2020) and preventive maintenance of historical buildings (Angjeliu et al., 2020). Facility management solutions enable owners to store, monitor, detect and communicate abnormalities associated with assets. To enhance anomaly detection within building systems, the Centre for Digital Built Britain (CDBB) proposed a national digital twin (NDT) that is more complex, diverse, and data-intensive than digital twins and allows for a more integrated and secure built environment (Lamb, 2019). To achieve this, CDBB proposed the integration of Gemini principles and digital twin techniques to developing the value-oriented NDT for the United Kingdom (UK). Xie et al. (2020) proposed a DT system that integrates diverse data sources from building components. The framework uses Bayesian algorithm to seek instances when there are changes in patterns of sensed data and illustrates differences between regular operations and actual anomalies. Qualitative data from visual assessments of building elements and quantitative data from structural health monitoring sensors (e.g., accelerometers and displacement transducers) describing the performance of historical buildings are collected and represented in the corresponding virtual structure to be viewed in VR.

\subsection{Limitations of current applications}

Despite the opportunities offered by CPS and DTs, there have been limited applications in the construction domain. Existing applications have marginally explored the full capabilities of CPS and DT. The virtual models employed in existing CPS applications do not adequately reflect the evolving state and behavior of physical construction components or processes. Instrumentation of projects provides access to data which, if integrated with historical project data, could be mined to develop models that will predict or drive the behavior of physical construction components, processes, and systems. Since the status of construction projects/constructed facilities changes with time, a variety of data are produced (e.g., videos, pictures, and texts) that could be used to improve the behavior of the models. When such models are consolidated with virtual designs, and tightly integrated with the physical construction/constructed facility, opportunities exist to optimize site operations and adjust physical processes through feedback and active control. This has implications for improving the constructability and maintainability of building and civil infrastructure systems while also informing future designs.

\section{NEXT GENERATION CPS AND DT IN CONSTRUCTION}

\subsection{Need for next generation systems}

Despite increasing efforts to improve construction project delivery practices, the industry still suffers from reduced productivity, safety, and quality issues. Several industry reports (Cappelli, 2015, Bakhshi et al., 2017, Institute, 2017) have reported marginal improvements in the construction sector compared with other industry sectors. Some of these have been attributed to the shortage of skilled trades, physically demanding nature of construction work, and high fatality rate of the industry. The United States (US) Bureau of Labor Statistics revealed that construction trades are 60\% more likely to sustain musculoskeletal injuries than other industries (BLS, 2020). In 2019, the construction industry experienced 1061 fatalities which accounted for about $20 \%$ of all occupational fatalities in the US (BLS, 2021). Cheng and Teizer (2013) posit that real-time monitoring of construction work can improve situational awareness and control. According to Yang et al. (2015), automated real-time supervision of construction activities can also improve instant awareness of pertinent issues on the jobsite. This can consequently improve construction labor and equipment productivity on the jobsite (Navon, 2005). In addition to the need to improve project delivery, there is the need for smart facility management strategies that will intelligently integrate 
construction data and facility management data for lifecycle management of buildings and civil infrastructure systems (Xu et al., 2020).

\subsection{Next generation CPS and DT in construction}

In the context of construction, CPS and DTs aim to realize the bi-directional communication and coordination between virtual models and the physical construction/constructed facility (Fig. 3). The virtual model can also be referred to as the DT if there exists a 2-way dynamic mapping with the physical construction/constructed facility. Through continuous data capture and integration, the DT's capability can be strengthened. Given the similarity in the twinning requirements of both concepts, CPS can be viewed as involving convergence and interaction between physical construction/constructed facility and its DT (Tao et al., 2018, Gabor et al., 2016). In this case, DT would represent the prerequisite for the development of a CPS. Such CPS would help the construction industry achieve better and more efficient decision making.

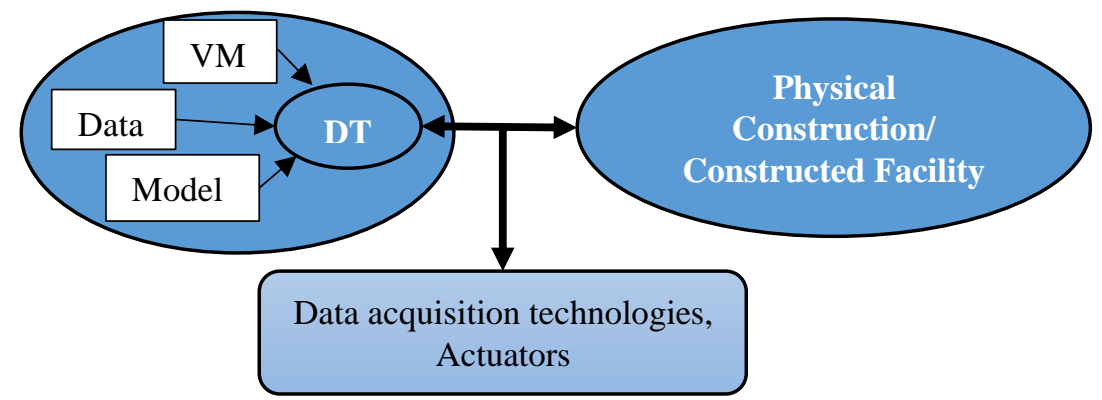

FIG. 3: Next generation CPS and DT (Adapted from Akanmu et al., 2013).

\subsection{Enabling technologies for next generation CPS and DT}

Since the inception of CPS and DT, the interest in both concepts has grown significantly. The growth has been largely driven by advances in computing technologies and techniques (Fig. 4) such as virtual modeling platforms, sensing technologies, data acquisition, data storage and data communication technologies, human-computer interaction technologies, and robotics. The trends in these technological developments and their potential roles in facilitating next generation CPS and DT applications are described below.

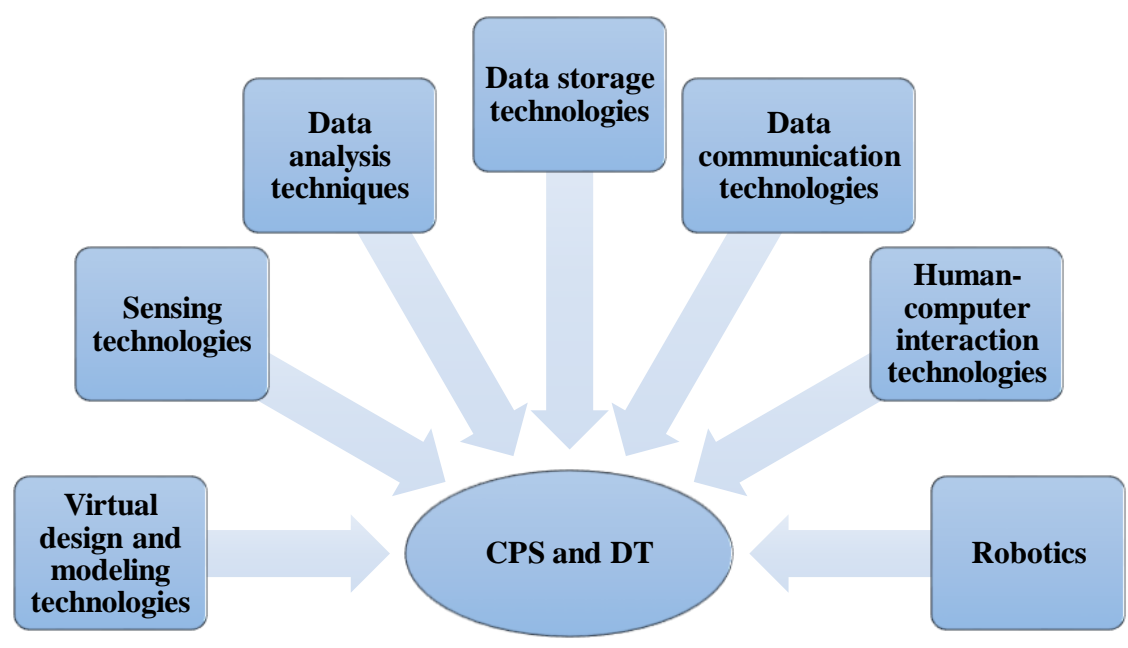

FIG. 4: Overview of enabling technologies and techniques for next generation CPS and DT. 


\subsubsection{Virtual design and modeling technologies}

Various virtual design and modeling platforms (e.g., BIM and game engines) exist for creating digital models and simulating construction work. BIM, which has gained significant recognition in the construction industry, serves as a platform for aggregating and storing interoperable building information. Within BIM, physical and functional properties of key components and systems related to project cost, schedule, specification, and maintenance can be embedded to enable lifecycle monitoring of facilities (Monteiro and Martins, 2013, Bradley et al., 2016). BIM is typically seen as the starting point for most CPS and DT applications, serving as a semantically rich platform for storing and representing sensed and historical data (Cecchini, 2019). With constant update from the physical environment, the BIM models can become replicas of physical components and composition of the physical construction/constructed facility providing behaviors and rules from manipulations of the sensed and historical data. The accuracy of BIM models affects the effectiveness of CPS and DTs for applications. When imported into reality simulation platforms (e.g., UNITY and UNREAL game engines), the resulting models can facilitate realtime simulations for executing what-if scenarios and decision making.

\subsubsection{Sensing technologies}

Sensing technologies are a key driver of CPS and DT applications. Sensors provide access to relevant information about facilities that are being constructed, resources and processes employed in the construction, and monitoring of the condition of the as-built throughout the lifecycle of the constructed facility (Akinci and Anumba, 2008). Sensors employed on construction projects can be classified as component-based and image-based sensing systems. The component-based sensing systems include RFID, inertial measurement units (IMUs), and global positioning system (GPS), while the image-based sensors include cameras and laser scanners. In construction, bar codes, RFID, IMUs, GPS, cameras, and laser scanners are the most widely used sensing technologies for information identification and real-time perception. For CPS and DT applications, since virtual models must coevolve with constant changes in the physical world, sensing technologies provide data that is critical for perceiving and cognizing the physical world. Through the sensors and data communication technologies, networks can be built between resources to connect and exchange data. Such data is significant for understanding relationships between processes, operations, and resources, and formulating models that can provide insight into the behavior of physical systems and for information quick decision making or control of the physical world.

\subsubsection{Data analysis techniques}

Data analysis within CPS and DT applications includes data processing and visualization. Historical and raw data obtained from the sensors are usually noisy and unstructured. These data need to be initially cleaned, smoothened, compressed and transformed for developing DTs (Kaur et al., 2020). The pre-processed data is analyzed using statistical methods (e.g., descriptive statistics, regression analysis, clustering analysis, time-series analysis, and dimension reduction) and neural networks (e.g., convolutional neural network, self-organizing network, and recurrent neural network). The deep learning networks are particularly useful for learning and identifying patterns from huge data (Wang et al., 2018). Data visualization techniques aim to present processed data in formats that are intuitive and suitable for quick decision making. Depending on the intended goal of the CPS and DT application, these data can be displayed within virtual models (e.g., BIM and game engines) or using as charts (e.g., dashboard, pie chart, histogram, and line chart). Given the intensive data requirements of CPS and DT, data processing and analysis can be server-based and edge-based. In server-based architecture, data acquired from the physical environment is processed and analyzed in a centralized server. While this may increase data latency, it is faster and easier to manage. In edge-based architectures, data analysis is performed at the 'edge' of the system. As a result, edge-based architecture typically has a low-latency but could be more challenging to maintain (Wang et al., 2019).

\subsubsection{Data storage technologies}

In addition to storing information in BIM, sensed and historical data are also stored in traditional databases and big data storage technologies for processing and simulation. Due to the volume and diversity of CPS and DT data sources, traditional databases such as Microsoft Excel, Access and SQL are usually unfeasible. Big data storage technologies, such as cloud storage, NewSQL and NoSQL databases, and distributed file storage (DFS) are now gaining attention (Khasawneh et al., 2020, Grolinger et al., 2013). Cloud storage enables storage of data on the Internet through cloud computing providers (e.g., Amazon, Google and Carbonite) who manage and operate the storage. NewSQL and NoSQL databases have the capability of storing and managing massive data while also 
providing support for traditional databases like SQL. With DFS, shared data relating to connected physical components can be accessed simultaneously over the network.

\subsubsection{Data communication technologies}

Data communication technologies include short- and long-range wireless communication technologies. Widely used short-range communication technologies in construction include Chirp-Spread Spectrum (Li et al., 2015), Wi-Fi (Chung et al., 2020), Bluetooth (Park et al., 2017), Ultra-wide band (Zhang et al., 2012), Zig-Bee (Jang and Skibniewski, 2007), and Near Field Communication (NFC) (Mohtat, 2016). Long-range communication technologies include satellite communication, spread spectrum microwave, and enhanced data rates for global system for mobile (GSM) communication evolution. These communication technologies enable access to data from distributed sensing systems and flow of data, eliminating barriers between project teams and phases. This provides a pathway for establishing relationships between processes and operations in construction work. Such data are stored in the data storage devices and improves the performance of the models generated with the data analysis techniques. With the move towards $5 \mathrm{G}$ communication networks and beyond, data transmission for CPS and DT systems will be significantly enhanced and may lead to new applications.

\subsubsection{Human-computer interaction technologies}

Human computer interaction technologies (e.g., VR and augmented reality (AR)) play significant roles in facilitating user interaction with DTs and CPS. VR technologies could offer immersive three-dimensional visualization of DTs, near-realistic rendering, gesture interactions, and collaboration functionalities using easily accessible navigation tools. With AR, DTs can be overlaid on the real world-environment (Lu Lu, 2019), while MR could merge the real and virtual environment or integrate DTs into a real environment (Pan et al., 2006). Users can focus on specific construction resources or an entire building or construction site. With advances in hardware and software systems, these technologies are becoming increasingly easier to deploy. They have been proposed in construction research for product or process design (Irizarry et al., 2012), training (Li et al., 2018, Chalhoub and Ayer, 2019), and collaboration amongst stakeholders (Mutis and Ambekar, 2020).

\subsubsection{Robotics}

Construction being a labor-intensive sector, is currently suffering from low unemployment and shortages of skilled labor (Kim et al., 2020). Robotic systems have been shown to be effective in other industry sectors for reducing labor costs while improving productivity (Fan et al., 2020, Ballestar et al., 2020). Robotic systems can reduce the productivity challenges and injuries (fatal and non-fatal) currently experienced in the construction industry, and reduce workers' exposure to unsafe and hazardous site conditions (Zhou et al., 2013, Carra et al., 2018). Construction robots can be broadly classified as industrial robots, drones, self-driving equipment, and exoskeletons. Sensed and analyzed data can be fed to robotic systems via the cyber-to-physical feature of next generation CPS and DT. For example, sensed data about worker performance can be learned and controls can be sent to robotic systems to facilitate collaborative work between humans and robots, enable robots perform construction tasks (e.g., bricklaying, drywalling and painting), and augment human activity using exoskeletons.

\subsection{New application areas for CPS and DT}

The enabling technologies described above will create a myriad of opportunities for the development and deployment of next generation CPS and DT systems in construction. This section presents three futuristic scenarios of such applications to illustrate the potential. The scenarios enable teleoperation of robots for drywall installation, postural tracking and control and near-miss prevention between workers and construction equipment. The presented scenarios are intended to illustrate improving workforce productivity, health and safety; advancing lifecycle management of building systems; and enhancing workforce competency.

\subsubsection{Teleoperation robots for drywall installation}

This scenario is intended to address the labor shortage, unsafe workplaces, and stagnant productivity currently experienced by the construction industry (Statistics, 2020). The scenario describes how by capturing workers' body movement (while performing installation tasks within virtual reality) using wearable IMUs and interpreting them into commands, robots can be controlled remotely to execute drywall installation tasks on the physical construction site. The scenario integrates BIM, image and component-based sensing technologies, virtual reality, and a robotic system, and is applicable in situations where the robots are required to undertake tasks by mimicking human actions. The key workflow is illustrated in Fig. 5. 
1. The physical work area, where the robot will be installing the drywall, is initially scanned with a laser scanner or any appropriate reality capture device. The scanned area will include the workspace and material staging area;

2. The physical work area and resources required for the drywall installation (e.g., drywall knife, saw, mud pan and drywalls) are modeled in BIM to develop a virtual representation of the workspace and resources;

3. The drywall installation resources are tagged with trackers to bind them with their virtual representation in the model. Other sensing technologies (e.g., IMUs and real-time location sensing technologies) can be utilized.

4. By binding the virtual and physical resources together, changes in one environment can be reflected in the other to make the virtual environment the DT;

5. The drywall installer is tagged with IMUs to track the movement of his/her body parts when performing installation tasks. Non-invasive vision-based motion capture devices can also be employed. The drywall installer is immersed in the virtual workspace via a VR head-mounted display, where he/she performs installation of drywalls using hand controllers or any haptic device;

6. As the installation is performed in the virtual space, movement data of the installer are captured and stored in a database server, where the data is interpreted to determine movements corresponding to the individual body parts;

7. Within the server, movement data of the physical installer are matched with the robot's body parts to initiate the same movements employed in executing the physical tasks. The movement of the robot's body parts are initiated via actuators;

Therefore, by tracking the movement of the worker's body parts and controlling the corresponding body part of the robot, CPS integration is achieved. Overtime, the movement data that are stored in the database server can be trained to recognize productive task movements and to train robots to self-perform construction tasks.

(2)

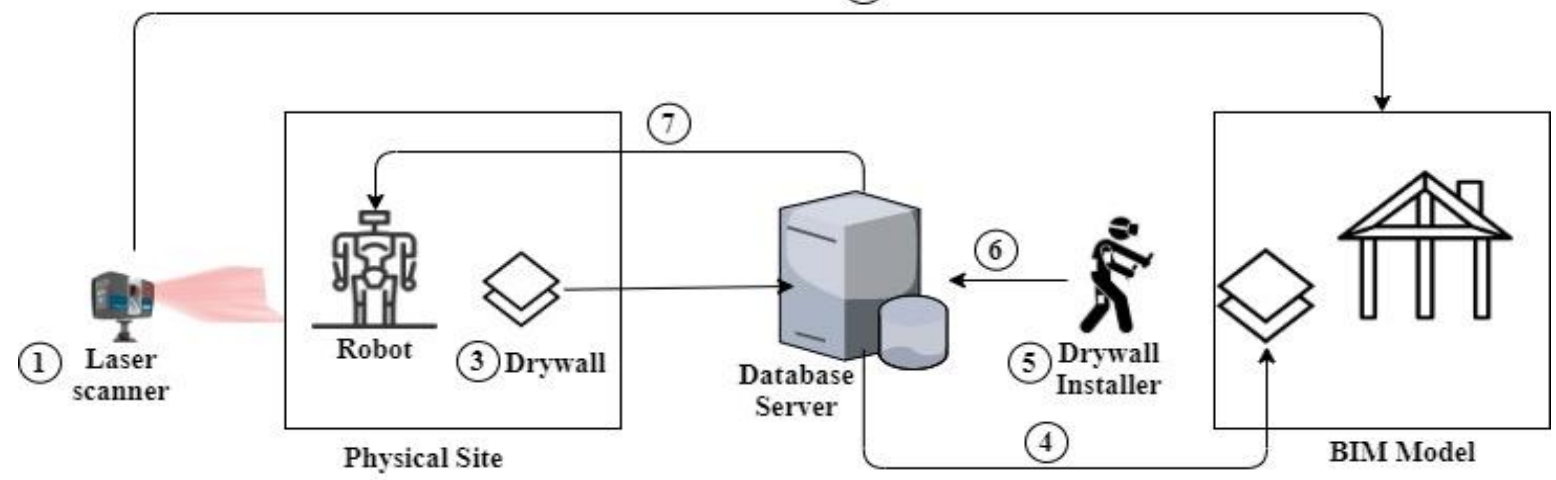

FIG. 5: Drywall installation using teleoperated robot.

\subsubsection{Postural tracking and control}

One way to reduce work-related musculoskeletal injuries is by providing workers with instant and personalized feedback to make them self-aware of the ergonomic exposures associated with their performance so that they can self-manage the exposures (Wang et al., 2015, Cheng et al., 2012, Chaffin et al., 1986, Yan et al., 2017). By responding to the feedback, workers can develop their competences in performing work in safe postures. This scenario, illustrated in Fig. 6, describes how workers' body movements and postures can be captured, their ergonomic risks are assessed and feedback is provided in the form of virtual body models or avatars of workers (also referred to as the DT). In this scenario, CPS integration is achieved by tightly integrating workers' physical body with their DT. This scenario integrates augmented reality, motion capture technology and machine learning to provide workers with real-time on-the-job feedback that would improve their performance. The key elements of this are illustrated in Fig 4 and described below:

1. A virtual body model of a worker is developed using an appropriate virtual modeling platform;

2. The worker's key body parts are strapped with IMUs to track the motions and posture of the body. Cameras can also be used if there is a line of sight to the worker;

3. While performing work, data from the IMU sensors are stored in a database on the server; 
4. A model, trained to recognize workers' tasks and postures from body motion data, is hosted on a server. This model classifies the tasks and postures from the data;

5. A rule algorithm determines the risk associated with the postures and represents this in the virtual replica of the workers as color codes (e.g., green, yellow, and red, representing no and low risk, medium risk, and high risk, respectively). These risks represent the level of ergonomic exposure identified in literature (Andrews et al., 2012). In this way, workers can understand the type and extent of the risk, affected body parts and can take corrective actions;

6. Workers can view this risk via their virtual model (as a DT), through an augmented reality (AR) head mounted display worn by the worker. As they continuously view their DT and respond to the risk, they develop their competencies in performing work safely.

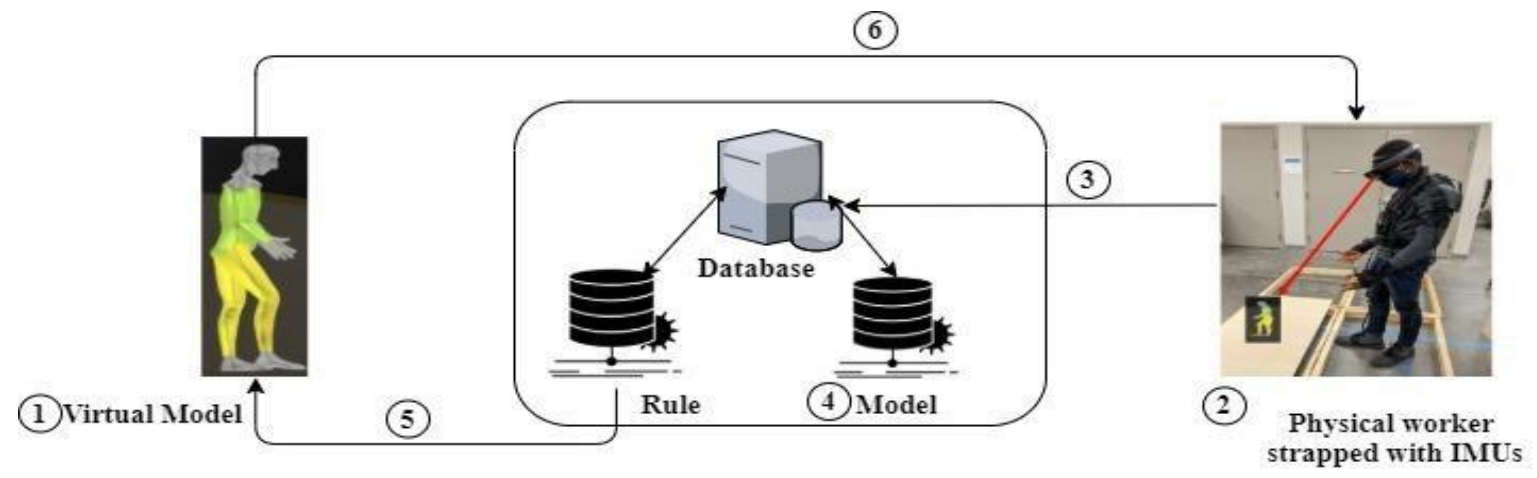

\section{FIG. 6: Postural learning environment.}

\subsubsection{Near-miss prevention between workers and construction equipment}

It is widely recognized that near-misses are a prerequisite for accidents, injuries or fatalities to occur. Safety managers are always looking for opportunities to identify potential near-misses before accidents, injuries or fatalities occur on construction sites. This scenario (shown in Fig. 7) describes how CPS integration of virtual and physical construction site layout (and resources) can help predict resource flow conditions, captured with component and vision-based sensors, which could cause near-misses on construction sites. If resource flow information that could cause a near-miss can be reliably predicted in real-time, it would be possible for project stakeholders to take preventive measures, such as rearranging the layout of the site, or providing appropriate warnings, signage or temporary barriers. The steps involved in this are shown in Fig. 7 and described below:

1. A BIM model of the layout of the construction site is created and hosted on a server. The BIM model will be viewable in the site office by the project team via a dashboard;

2. A drone (or other suitable reality capture technology) is employed to capture aerial views of the site. Hardhats of workers are also equipped with $360^{\circ}$ videos to capture any changes in layout as the workers move around the site. The image data from the site are sent to a database hosted on the server;

3. An object detection algorithm, previously trained to detect construction resources, running on the server is initiated to recognize interesting site features and resources (e.g., materials and equipment) from the video images;

4. The BIM model is updated with the recognized site features and resources to represent an up-to-date model of the site;

5. Workers and equipment are tagged with real-time location sensors to track their spatiotemporal location on the site. The spatiotemporal information is sent wirelessly to a database on the server;

6. A case based reasoning (CBR) model trained to classify near-miss cases from the historical near-miss data is hosted on the server. The classification can be based on the type of resources, equipment involved (e.g. mobile crane, excavator, dump truck, etc.), causes, and variables (e.g., time and location of occurrence, and any other spatio-temporal information);

7. A K-nearest neighbor (KNN) algorithm hosted on the server determines any similarity between the realtime resource flow data and the classified near-miss cases, and then predicts potential near-misses.

8. Based on the prediction, control messages are sent to the BIM model to represent the near-misses. This is represented in the context of the affected resources, and location, and estimated time of occurrence. The BIM model showing the near-miss information can be viewed via the dashboard by project stakeholders. 


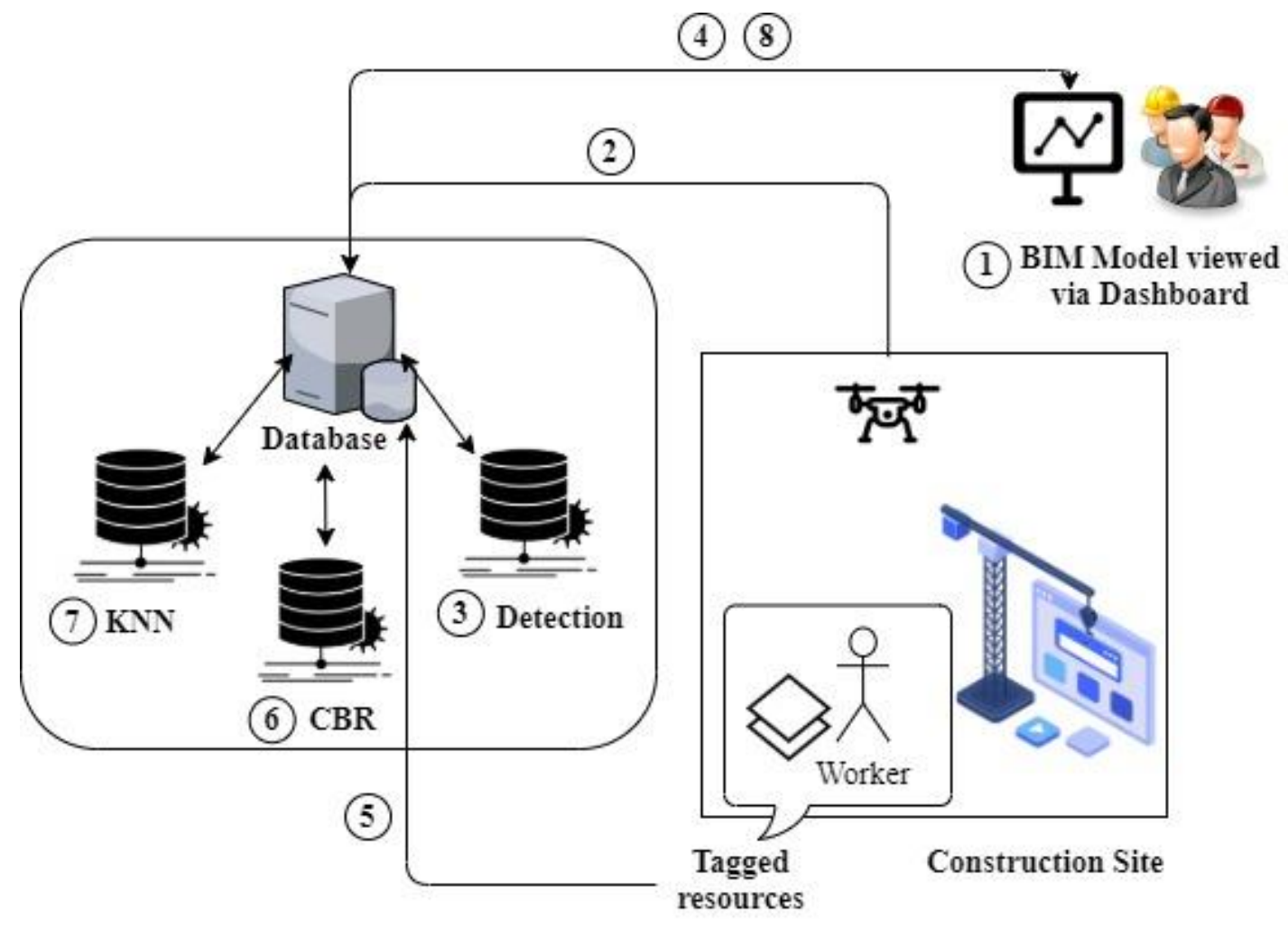

FIG. 7: Near-miss prediction.

\section{DISCUSSION AND CONCLUSIONS}

With advances in data acquisition systems, information technology, and networking technologies, the unique characteristics of CPS and DT can be leveraged to create the next generation CPS and DT capable of facilitating a more effective integration of virtual models and the physical construction/constructed facility. The next generation CPS and DT described in this paper involves making changes to the foundational composition of CPS by harnessing the potentials of emerging technologies and techniques. It also argues for more strategic efforts towards enhancing the capabilities of existing virtual design platforms to achieve DTs enriched with data to create opportunities for more informed decision making and active control. The key enabling technologies are presented and their role in facilitating this next generation CPS and DTs has been demonstrated through the development of application scenarios. Despite the benefits of the next generation CPS and DTs, a few challenges need to be addressed to advance the implementation of their applications in construction.

Firstly, a complete DT is needed for achieving acceptable accuracy in the next generation CPS and DTs. There is currently no established information model for DT applications. Such information models will illustrate semantics of any relationships, rules and constraints from data that is critical for understanding the behavior of physical systems and artifacts. This is a necessary ingredient for the implementation of the next generation CPS and DT applications. Secondly, as DTs can evolve due to changes in the state of the corresponding physical component or system, there need to be guidelines for defining and managing the different versions. The stages at which the versions should be captured, stored, and integrated should be defined. This is significant for effectively managing the DT models. Thirdly, data communication latency between DTs and the physical component/system is critical for achieving timely decision making and could be application-dependent. However, there is currently no established guideline for data communication latency in construction applications. For example, a stringent communication latency will be required for applications where workers need to be informed of their unsafe postures while performing work so that they can quickly self-manage their exposures, whereas a more flexible latency may be acceptable during the generation of models for long time learning of data patterns. Fourthly, where the data obtained from physical components are stored and analyzed could affect data communication latency and processing cost. Although, server computing is easy to maintain, its data processing latency is higher than in edge computing which has a lower latency but is more challenging to maintain. Another challenge is that there are 
currently limited standards for enabling interoperability between design platforms and information models. This is significant for applications that will benefit from a network of DTs of different construction companies or sites. Such interoperability standards would be analogous to the Industry Foundation Classes (IFC) employed in BIM interoperability (Vanlande et al., 2008).

The next generation CPS and DT provides a unique opportunity to achieve more effective cyber-physical integration. The following are the key conclusions that can be drawn from this work: There is currently a missed opportunity to develop DTs from virtual design models using data obtained from physical systems and the environment for improving the lifecycle of facilities. Two-way CPS integration between the DTs and physical systems offer tremendous potential for improving predictability and control. Key enabling technologies include virtual design modeling technologies, sensing technologies, data analysis, storage and communication technologies, human-computer interaction technologies, and robotics. Next generation CPS and DTs have considerable potential for improving workforce productivity, health and safety; improving lifecycle management of building systems; and enhancing workforce competency.

\section{REFERENCES}

Akanmu, A., Anumba, C. and Messner, J. (2013). Scenarios for cyber-physical systems integration in construction, Journal of Information Technology in Construction (ITcon), Vol. 18, No. 12, 240-260.

Akanmu, A., Anumba, C. and Messner, J. (2014). Active monitoring and control of light fixtures during building construction and operation: Cyber-physical systems approach, Journal of Architectural Engineering, Vol. 20, No. 2, 04013008.

Akanmu, A. and Anumba, C. J. (2015). Cyber-physical systems integration of building information models and the physical construction, Engineering, Construction and Architectural Management, Vol. 22, No. 5, 516535 .

Akanmu, A. A., Olayiwola, J., Ogunseiju, O. and Mcfeeters, D. (2020). Cyber-physical postural training system for construction workers, Automation in Construction, Vol. 117, 103272.

Akinci, B. and Anumba, C. (2008). Sensors in construction and infrastructure management, Journal of Information Technology in Construction (ITcon), Vol. 13, No. 5, 69-70.

Albers, J. T. (2007). Simple solutions: Ergonomics for construction workers, US Department of Health and Human Services, Public Health Service, Centers ....

Andrews, D. M., Fiedler, K. M., Weir, P. L. and Callaghan, J. P. (2012). The effect of posture category salience on decision times and errors when using observation-based posture assessment methods, Ergonomics, Vol. 55, No. 12, 1548-1558.

Angjeliu, G., Coronelli, D. and Cardani, G. (2020). Development of the simulation model for Digital Twin applications in historical masonry buildings: The integration between numerical and experimental reality, Computers \& Structures, Vol. 238, 106282.

Anumba, C. J., Akanmu, A. and Messner, J. Towards a cyber-physical systems approach to construction, Construction research congress 2010: Innovation for reshaping construction practice, 2010. 528-537.

Anumba, C. J., Akanmu, A., Yuan, X. and Kan, C. (2021). Cyber-physical systems development for construction applications, Frontiers of Engineering Management, Vol. 8, No. 1, 72-87.

Asadi, K., Suresh, A. K., Ender, A., Gotad, S., Maniyar, S., Anand, S., Noghabaei, M., Han, K., Lobaton, E. and $\mathrm{Wu}, \mathrm{T}$. (2020). An integrated UGV-UAV system for construction site data collection, Automation in Construction, Vol. 112, 103068.

Bakhshi, H., Downing, J. M., Osborne, M. A. and Schneider, P. (2017). The future of skills: Employment in 2030, Pearson.

Ballestar, M. T., Díaz-Chao, Á., Sainz, J. and Torrent-Sellens, J. (2020). Knowledge, robots and productivity in SMEs: Explaining the second digital wave, Journal of Business Research, Vol. 108, 119-131.

Barrett, P. and Baldry, D. (2009). Facilities management: Towards best practice, John Wiley \& Sons. 
Bls, B. O. L. S. 2020. Nonfatal Occupational Injuries and Illnesses Requiring Days Away from Work [Online]. Available: https://data.bls.gov/PDQWeb/cs [Accessed 8th February 2021].

Bls, B. O. L. S. 2021. Databases, Tables \& Calculators by Subject [Online]. Available: https://data.bls.gov/pdq/SurveyOutputServlet [Accessed 6th February 2021].

Boje, C., Guerriero, A., Kubicki, S. and Rezgui, Y. (2020). Towards a semantic Construction Digital Twin: Directions for future research, Automation in Construction, Vol. 114, No. 103179.

Bonci, A., Carbonari, A., Cucchiarelli, A., Messi, L., Pirani, M. and Vaccarini, M. (2019). A cyber-physical system approach for building efficiency monitoring, Automation in Construction, Vol. 102, 68-85.

Boschert, S. and Rosen, R. 2016. Digital twin — the simulation aspect. Mechatronic futures. Springer.

Bottani, E., Cammardella, A., Murino, T. and Vespoli, S. 2017. From the Cyber-Physical System to the Digital Twin: the process development for behaviour modelling of a Cyber Guided Vehicle in M2M logic. XXII Summer School Francesco TurcoIndustrial Systems Engineering.

Bradley, A., Li, H., Lark, R. and Dunn, S. (2016). BIM for infrastructure: An overall review and constructor perspective, Automation in Construction, Vol. 71, 139-152.

Brenner, B. and Hummel, V. (2017). Digital twin as enabler for an innovative digital shopfloor management system in the ESB Logistics Learning Factory at Reutlingen-University, Procedia Manufacturing, Vol. 9, 198-205.

Broy, M. 2013. Engineering cyber-physical systems: Challenges and foundations. Complex Systems Design \& Management. Springer.

Cappelli, P. H. (2015). Skill gaps, skill shortages, and skill mismatches: Evidence and arguments for the United States, ILR Review, Vol. 68, No. 2, 251-290.

Carra, G., Argiolas, A., Bellissima, A., Niccolini, M. and Ragaglia, M. Robotics in the construction industry: state of the art and future opportunities, ISARC. Proceedings of the International Symposium on Automation and Robotics in Construction, 2018. IAARC Publications, 1-8.

Cecchini, C. (2019). From data to 3D digital archive: a GIS-BIM spatial database for the historical centre of Pavia (Italy), ITcon, Vol. 24, 459-471.

Chaffin, D. B., Gallay, L. S., Woolley, C. B. and Kuciemba, S. R. (1986). An evaluation of the effect of a training program on worker lifting postures, International Journal of Industrial Ergonomics, Vol. 1, No. 2, $127-$ 136.

Chalhoub, J. and Ayer, S. K. (2019). Effect of varying task attributes on augmented reality aided point layout, ITcon, Vol. 24, 95-111.

Cheng, T., Migliaccio, G. C., Teizer, J. and Gatti, U. C. (2012). Data fusion of real-time location sensing and physiological status monitoring for ergonomics analysis of construction workers, Journal of Computing in Civil engineering, Vol. 27, No. 3, 320-335.

Cheng, T. and Teizer, J. (2013). Real-time resource location data collection and visualization technology for construction safety and activity monitoring applications, Automation in construction, Vol. 34, 3-15.

Chung, W. W. S., Tariq, S., Mohandes, S. R. and Zayed, T. (2020). IoT-based application for construction site safety monitoring, International Journal of Construction Management, 1-17.

Eskandar, S., Wang, J. and Razavi, S. 2020. Human-in-the-Loop Cyber-Physical Systems for Construction Safety. In: Anumba, C. J. \& Roofigari-Esfahan, N. (eds.) Cyber-Physical Systems in the Built Environment. Cham: Springer International Publishing.

Fan, H., Hu, Y. and Tang, L. (2020). Labor costs and the adoption of robots in China, Journal of Economic Behavior \& Organization.

Fawzi, H., Tabuada, P. and Diggavi, S. (2014). Secure estimation and control for cyber-physical systems under adversarial attacks, IEEE Transactions on Automatic control, Vol. 59, No. 6, 1454-1467.

Fu, Z., Guo, C., Ren, S., Ou, Y. and Sha, L. Modeling and integrating human interaction assumptions in medical cyber-physical system design, 2017 IEEE 30th International Symposium on Computer-Based Medical 
Systems (CBMS), 2017. IEEE, 373-378.

Gabor, T., Belzner, L., Kiermeier, M., Beck, M. T. and Neitz, A. A simulation-based architecture for smart cyberphysical systems, 2016 IEEE international conference on autonomic computing (ICAC), 2016. IEEE, 374379.

Genders, W., Wang, J. and Razavi, S. Smartphone construction safety awareness system: A cyber-physical system approach, In The 16th International Conference on Computing in Civil and Building Engineering (ICCCBE2016), 2016.

Glaessgen, E. and Stargel, D. The digital twin paradigm for future NASA and US Air Force vehicles, 53rd AIAA/ASME/ASCE/AHS/ASC structures, structural dynamics and materials conference 20th AIAA/ASME/AHS adaptive structures conference 14th AIAA, 2012. 1818.

Greif, T., Stein, N. and Flath, C. M. (2020). Peeking into the void: Digital twins for construction site logistics, Computers in Industry, Vol. 121, 103264.

Grieves, M. (2014). Digital twin: manufacturing excellence through virtual factory replication, White paper, Vol. $1,1-7$.

Grieves, M. and Vickers, J. 2017. Digital twin: Mitigating unpredictable, undesirable emergent behavior in complex systems. Transdisciplinary perspectives on complex systems. Springer.

Grolinger, K., Higashino, W. A., Tiwari, A. and Capretz, M. A. (2013). Data management in cloud environments: NoSQL and NewSQL data stores, Journal of Cloud Computing: advances, systems and applications, Vol. 2, No. 1, 1-24.

Gunes, V., Peter, S., Givargis, T. and Vahid, F. (2014). A survey on concepts, applications, and challenges in cyberphysical systems, KSII Transactions on Internet \& Information Systems, Vol. 8, 12.

Hou, Y., Zhao, Y., Wagh, A., Zhang, L., Qiao, C., Hulme, K. F., Wu, C., Sadek, A. W. and Liu, X. (2015). Simulation-based testing and evaluation tools for transportation cyber-physical systems, IEEE Transactions on Vehicular Technology, Vol. 65, No. 3, 1098-1108.

Hu, L., Xie, N., Kuang, Z. and Zhao, K. Review of cyber-physical system architecture, 2012 IEEE 15th International Symposium on Object/Component/Service-Oriented Real-Time Distributed Computing Workshops, 2012. IEEE, 25-30.

Institute, M. G. 2017. Reinventing Construction: A Route to Higher Productivity.

Irizarry, J., Gheisari, M. and Walker, B. N. (2012). Usability assessment of drone technology as safety inspection tools, Journal of Information Technology in Construction (ITcon), Vol. 17, No. 12, 194-212.

Jang, W.-S. and Skibniewski, M. J. Wireless sensor technologies for automated tracking and monitoring of construction materials utilizing Zigbee networks, ASCE Construction Research Congress: The Global Construction Community, 2007. 6-8.

Jiang, H., Qin, S., Fu, J., Zhang, J. and Ding, G. (2020a). How to model and implement connections between physical and virtual models for digital twin application, Journal of Manufacturing Systems, Vol. 58, 36-51.

Jiang, W., Ding, L. and Zhou, C. (2020b). Cyber physical system for safety management in smart construction site, Engineering, Construction and Architectural Management.

Kan, C. and Anumba, C. 2019. Digital twins as the next phase of cyber-physical systems in construction. Computing in civil engineering 2019: Data, sensing, and analytics. American Society of Civil Engineers Reston, VA.

Karakra, A., Fontanili, F., Lamine, E. and Lamothe, J. HospiT'Win: A Predictive Simulation-Based Digital Twin for Patients Pathways in Hospital, 2019 IEEE EMBS International Conference on Biomedical \& Health Informatics (BHI), 2019. IEEE, 1-4.

Kaur, M. J., Mishra, V. P. and Maheshwari, P. 2020. The convergence of digital twin, IoT, and machine learning: transforming data into action. Digital twin technologies and smart cities. Springer.

Kavulya, G., Gerber, D. J. and Becerik-Gerber, B. (2011). Designing in complex system interaction: Multi-agent based systems for early design decision making, Proceedings of the 28th ISARC International Association 
for Automation and Robotics in Construction, Seoul, Korea, 694-698.

Khasawneh, T. N., Al-Sahlee, M. H. and Safia, A. A. SQL, NewSQL, and NOSQL Databases: A Comparative Survey, 2020 11th International Conference on Information and Communication Systems (ICICS), 2020. IEEE, 013-021.

Kim, S., Chang, S. and Castro-Lacouture, D. (2020). Dynamic modeling for analyzing impacts of skilled labor shortage on construction project management, Journal of Management in Engineering, Vol. 36, No. 1, 04019035 .

Kritzinger, W., Karner, M., Traar, G., Henjes, J. and Sihn, W. (2018). Digital Twin in manufacturing: A categorical literature review and classification, IFAC-PapersOnLine, Vol. 51, No. 11, 1016-1022.

Lamb, K. (2019). Principle-based digital twins: a scoping review.

Lee, E. A. and Seshia, S. A. (2011). Introduction to embedded systems, A cyber-physical systems approach, Vol. 499, 178-183.

Lee, J., Azamfar, M., Singh, J. and Siahpour, S. (2020). Integration of digital twin and deep learning in cyberphysical systems: towards smart manufacturing, IET Collaborative Intelligent Manufacturing, Vol. 2, No. 1, 34-36.

Lee, J., Bagheri, B. and Kao, H.-A. (2015). A cyber-physical systems architecture for industry 4.0-based manufacturing systems, Manufacturing letters, Vol. 3, 18-23.

Li, H., Chan, G., Huang, T., Skitmore, M., Tao, T. Y., Luo, E., Chung, J., Chan, X. and Li, Y. (2015). Chirp-spreadspectrum-based real time location system for construction safety management: A case study, Automation in construction, Vol. 55, No. 58-65.

Li, X., Yi, W., Chi, H.-L., Wang, X. and Chan, A. P. (2018). A critical review of virtual and augmented reality (VR/AR) applications in construction safety, Automation in Construction, Vol. 86, 150-162.

Lin, J. J. and Golparvar-Fard, M. 2020. Construction Progress Monitoring Using Cyber-Physical Systems. In: Anumba, C. J. \& Roofigari-Esfahan, N. (eds.) Cyber-Physical Systems in the Built Environment. Cham: Springer International Publishing.

Liu, C., Jiang, P. and Jiang, W. (2020a). Web-based digital twin modeling and remote control of cyber-physical production systems, Robotics and computer-integrated manufacturing, Vol. 64, 101956.

Liu, D., Liang, J., Chen, J., Chu, D. and Li, S. A Cyber-Physical System for Multi-Roller Control in Mega Infrastructure Projects, Construction Research Congress 2020: Project Management and Controls, Materials, and Contracts, 2020b. American Society of Civil Engineers Reston, VA, 418-426.

Liu, G., Yang, H., Fu, Y., Mao, C., Xu, P., Hong, J. and Li, R. (2020c). Cyber-physical system-based real-time monitoring and visualization of greenhouse gas emissions of prefabricated construction, Journal of Cleaner Production, Vol. 246, 119059.

Liu, Y., Peng, Y., Wang, B., Yao, S. and Liu, Z. (2017). Review on cyber-physical systems, IEEE/CAA Journal of Automatica Sinica, Vol. 4, No. 1, 27-40.

Liu, Y., Zhang, L., Yang, Y., Zhou, L., Ren, L., Wang, F., Liu, R., Pang, Z. and Deen, M. J. (2019). A novel cloudbased framework for the elderly healthcare services using digital twin, IEEE Access, Vol. 7, 49088-49101.

Lu, C., Saifullah, A., Li, B., Sha, M., Gonzalez, H., Gunatilaka, D., Wu, C., Nie, L. and Chen, Y. (2015). Realtime wireless sensor-actuator networks for industrial cyber-physical systems, Proceedings of the IEEE, Vol. 104 , No. 5, 1013-1024.

Lu Lu, A. (2019). Large Scale Immersive Holograms with Microsoft Hololens.

Lu, Y., Liu, C., Kevin, I., Wang, K., Huang, H. and Xu, X. (2020). Digital Twin-driven smart manufacturing: Connotation, reference model, applications and research issues, Robotics and Computer-Integrated Manufacturing, Vol. 61, 101837.

Melenbrink, N., Werfel, J. and Menges, A. (2020). On-site autonomous construction robots: Towards unsupervised building, Automation in Construction, Vol. 119, No. 103312. 
Mohtat, A. G. (2016). Construction material tracking inventory control system using smart Bluetooth/NFC tracking devices, Illinois Institute of Technology.

Möller, D. P. and Vakilzadian, H. Cyber-physical systems in smart transportation, 2016 IEEE International Conference on Electro Information Technology (EIT), 2016. IEEE, 0776-0781.

Monteiro, A. and Martins, J. P. (2013). A survey on modeling guidelines for quantity takeoff-oriented BIM-based design, Automation in construction, Vol. 35, No. 238-253.

Moore, S. M., Torma-Krajewski, J. and Steiner, L. J. 2011. Practical demonstrations of ergonomic principles [Online]. Available: https://stacks.cdc.gov/view/cdc/57870 [Accessed 18th December 2021].

Mutis, I. and Ambekar, A. (2020). Challenges and enablers of augmented reality technology for in situ walkthrough applications, ITcon, Vol. 25, 55-71.

Navon, R. (2005). Automated project performance control of construction projects, Automation in construction, Vol. 14, No. 4, 467-476.

Ogunseiju, O., Olayiwola, J. and Akanmu, A. 2020. Digital Twins Driven Musculoskeletal Injury Prevention System. 20th International Conference on Construction Applications of Virtual Reality (CONVR 2020) Middlesbrough, United Kingdom.

Olatunji, O. A. and Akanmu, A. A. (2015). An adaptive cyber-physical system's approach to construction progress monitoring and control, Building Information Modeling, Vol., No. 195.

Pan, Z., Cheok, A. D., Yang, H., Zhu, J. and Shi, J. (2006). Virtual reality and mixed reality for virtual learning environments, Computers \& graphics, Vol. 30, No. 1, 20-28.

Park, J., Kim, K. and Cho, Y. K. (2017). Framework of automated construction-safety monitoring using cloudenabled BIM and BLE mobile tracking sensors, Journal of Construction Engineering and Management, Vol. 143, No. 2, 05016019.

Park, K. T., Lee, J., Kim, H.-J. and Do Noh, S. (2020). Digital twin-based cyber physical production system architectural framework for personalized production, The International Journal of Advanced Manufacturing Technology, Vol. 106, No. 5, 1787-1810.

Pradhananga, N. and Teizer, J. (2013). Automatic spatio-temporal analysis of construction site equipment operations using GPS data, Automation in Construction, Vol. 29, No. 107-122.

Rajkumar, R., Lee, I., Sha, L. and Stankovic, J. Cyber-physical systems: the next computing revolution, Design automation conference, 2010. IEEE, 731-736.

Rao, A., Carreón, N., Lysecky, R. and Rozenblit, J. (2017). Probabilistic threat detection for risk management in cyber-physical medical systems, IEEE Software, Vol. 35, No. 1, 38-43.

Rosen, R., Von Wichert, G., Lo, G. and Bettenhausen, K. D. (2015). About the importance of autonomy and digital twins for the future of manufacturing, IFAC-PapersOnLine, Vol. 48, No. 3, 567-572.

Sampigethaya, K. and Poovendran, R. (2013). Aviation cyber-physical systems: Foundations for future aircraft and air transport, Proceedings of the IEEE, Vol. 101, No. 8, 1834-1855.

Sanislav, T. and Miclea, L. (2012). Cyber-physical systems-concept, challenges and research areas, Journal of Control Engineering and Applied Informatics, Vol. 14, No. 2, 28-33.

Schleich, B., Anwer, N., Mathieu, L. and Wartzack, S. (2017). Shaping the digital twin for design and production engineering, CIRP Annals, Vol. 66, No. 1, 141-144.

Schmidt, M. and Åhlund, C. (2018). Smart buildings as Cyber-Physical Systems: Data-driven predictive control strategies for energy efficiency, Renewable and Sustainable Energy Reviews, Vol. 90, No. 742-756.

Sivanathan, A., Abdel-Wahab, M., Bosche, F. and Lim, T. Towards a cyber-physical gaming system for training in the construction and engineering industry, ASME 2014 International Design Engineering Technical Conferences and Computers and Information in Engineering Conference, 2014. American Society of Mechanical Engineers Digital Collection.

Statistics, B. O. L. 2020. National Census of Fatal Occupational Injuries in 2019 [Online]. Available: 
https://www.bls.gov/news.release/pdf/cfoi.pdf [Accessed 28th February 2021].

Tao, F., Cheng, J., Qi, Q., Zhang, M., Zhang, H. and Sui, F. (2018). Digital twin-driven product design, manufacturing and service with big data, The International Journal of Advanced Manufacturing Technology, Vol. 94, No. 9, 3563-3576.

Tao, F., Qi, Q., Wang, L. and Nee, A. (2019). Digital twins and cyber-physical systems toward smart manufacturing and industry 4.0: Correlation and comparison, Engineering, Vol. 5, No. 4, 653-661.

Terreno, S., Akanmu, A., Anumba, C. J. and Olayiwola, J. 2020. Cyber-Physical Social Systems for Facility Management. In: Anumba, C. J. \& Roofigari-Esfahan, N. (eds.) Cyber-Physical Systems in the Built Environment. Cham: Springer International Publishing.

Tharma, R., Winter, R. and Eigner, M. An approach for the implementation of the digital twin in the automotive wiring harness field, DS 92: Proceedings of the DESIGN 2018 15th International Design Conference, 2018. 3023-3032.

Vanlande, R., Nicolle, C. and Cruz, C. (2008). IFC and building lifecycle management, Automation in construction, Vol. 18, No. 1, 70-78.

Vatn, J. Industry 4.0 and real-time synchronization of operation and maintenance, Safety and Reliability-Safe Societies in a Changing World-Proceedings of the 28th International European Safety and Reliability Conference, ESREL 2018, 2018. 681-686.

Wagner, R., Schleich, B., Haefner, B., Kuhnle, A., Wartzack, S. and Lanza, G. (2019). Challenges and potentials of digital twins and Industry 4.0 in product design and production for high performance products, Procedia CIRP, Vol. 84, 88-93.

Wan, J., Yan, H., Suo, H. and Li, F. (2011). Advances in cyber-physical systems research, KSII Transactions on Internet and Information Systems (TIIS), Vol. 5, No. 11, 1891-1908.

Wang, D., Dai, F. and Ning, X. (2015). Risk assessment of work-related musculoskeletal disorders in construction: state-of-the-art review, Journal of Construction Engineering and management, Vol. 141, No. 6, 04015008.

Wang, J., Abid, H., Lee, S., Shu, L. and Xia, F. (2011). A secured health care application architecture for cyberphysical systems, arXiv preprint arXiv:1201.0213.

Wang, J., Ma, Y., Zhang, L., Gao, R. X. and Wu, D. (2018). Deep learning for smart manufacturing: Methods and applications, Journal of Manufacturing Systems, Vol. 48, 144-156.

Wang, J., Wu, W., Liao, Z., Sangaiah, A. K. and Sherratt, R. S. (2019). An energy-efficient off-loading scheme for low latency in collaborative edge computing, IEEE Access, Vol. 7, 149182-149190.

Xie, X., Lu, Q., Parlikad, A. K. and Schooling, J. M. (2020). Digital Twin Enabled Asset Anomaly Detection for Building Facility Management, IFAC-PapersOnLine, Vol. 53, No. 3, 380-385.

Xu, J., Lu, W., Anumba, C. J. and Niu, Y. 2020. From Smart Construction Objects to Cognitive Facility Management. In: Anumba, C. J. \& Roofigari-Esfahan, N. (eds.) Cyber-Physical Systems in the Built Environment. Cham: Springer International Publishing.

Yan, X., Li, H., Li, A. R. and Zhang, H. (2017). Wearable IMU-based real-time motion warning system for construction workers' musculoskeletal disorders prevention, Automation in Construction, Vol. 74, 2-11.

Yang, J., Park, M.-W., Vela, P. A. and Golparvar-Fard, M. (2015). Construction performance monitoring via still images, time-lapse photos, and video streams: Now, tomorrow, and the future, Advanced Engineering Informatics, Vol. 29, No. 2, 211-224.

Yongfu, L., Dihua, S., Weining, L. and Xuebo, Z. A service-oriented architecture for the transportation cyberphysical systems, Proceedings of the 31st Chinese Control Conference, 2012. IEEE, 7674-7678.

You, Z. and Feng, L. (2020). Integration of industry 4.0 related technologies in construction industry: a framework of cyber-physical system, IEEE Access, Vol. 8, No. 122908-122922.

Yuan, X., Anumba, C. J. and Parfitt, M. K. Real-time Cyber-Physical Systems (CPS)-based monitoring of temporary structures: A scaffolding system example, Proceedings of the 32nd CIB W78 Conference 2015, 27-29 October, Eindhoven, the Netherlands, 2014. 780-789. 
Zhang, C., Hammad, A. and Rodriguez, S. (2012). Crane pose estimation using UWB real-time location system, Journal of Computing in Civil Engineering, Vol. 26, No. 5, 625-637.

Zhou, Z., Irizarry, J. and Li, Q. (2013). Applying advanced technology to improve safety management in the construction industry: a literature review, Construction Management and Economics, Vol. 31, No. 6, 606622.

Zhu, Z., Park, M.-W., Koch, C., Soltani, M., Hammad, A. and Davari, K. (2016). Predicting movements of onsite workers and mobile equipment for enhancing construction site safety, Automation in Construction, Vol. 68, 95-101. 